\title{
Observations on e-Business Implementation Capabilities in Heterogeneous Business Networks
}

\author{
Tero Pesonen and Kari Smolander \\ Lappeenranta University of Technology, Skinnarilankatu 34, \\ 53850 Lappeenranta, Finland \\ \{Tero.Pesonen, Kari.Smolander\} @lut.fi
}

\begin{abstract}
The objective of this qualitative study was to understand the factors that hinder large industry organizations in implementing e-Business solutions. The study included 4 organizations that operated in heterogeneous business networks consisting also of small partners. Interviews were conducted with managers of IT, purchasing and business development. The results indicate that the organizations faced a mixture of intertwined, accumulative challenges. Lack of IT resources and growing reliance on third parties had reduced IT expertise and made investments difficult. At the same time, e-Business projects were found to be very demanding to plan and execute, and with no e-Business knowledge or conscious e-Business strategies in place, the organizations were progressing haphazardly. The heterogeneous business environment also posed external challenges with partners having highly-disparate IT capabilities. Existing e-Business technologies appeared either inadequate for the needs of these networks or the appropriate technology was entirely missing.
\end{abstract}

Keywords: e-Business, e-Business implementation, interoperability, IT implementation, inter-organizational systems.

\section{Introduction}

E-Business can be defined as the use of information technology in support of more efficient business interactions between two or more organizations or organization units [6]. e-Business therefore relates not only to specific information technologies, but also to collaboration, either internal or inter-organizational. According to traditional collaboration schemes, transaction-oriented relationships between organizations in supply chains have led companies into trying to take advantage of one another in order to maximize their own utility. In such a context, companies see themselves as buyers of goods and sellers of value-added goods [2]. The first eBusiness applications, based on the EDI (Electronic Data Interchange) standard [3, 4, 5], aimed to make these basic, high-volume interactions taking place between business partners - for example, a buyer and seller - electronic and more automated. EDI standards replaced print documents sent by mail with electronic documents exchanged directly between IT systems. This allowed for removing manual work and errors and for reducing clerical costs $[6,7,12]$. Modern e-Business technologies, such 
as RosettaNet-like business-to-business integration (B2Bi) frameworks, have since built on these objectives by offering richer, platform neutral business data formats and support for fully-automatic business processes that can be integrated between collaborating partners $[1,8,9]$. Recently, Web Services and other cloud computing technologies have also emerged, but not so much as direct e-Business tools or applications as alternative e-Business development platforms that allow software to span traditional organizational boundaries [10, 11, 34].

Despite these technological developments, e-Business has failed to reach the level of sophistication and adoption originally predicted [6]. While the use of internet for business has become ubiquitous in developed economies, and wholly new business models, such those made prevalent by Google and other internet-based companies, have become pervasive [24], the actual business interactions between organizations have changed slowly [13]. Deep supply chain collaboration has failed to materialise [30], and still only a portion of the industry makes use of any kind of e-Business technology at all $[6,13,14]$.

In this study, our objective is to observe large industry organizations in order to understand what the factors are that hinder them in implementing e-Business solutions for more efficient B2B integration. The organizations represent traditional, non-IT industries and operate in heterogeneous business networks that comprise also smaller suppliers and buyers. Our study is qualitative, as understanding e-Business implementation constraints requires exploration in socio-technical real-world contexts.

We have structured our paper as follows: We first review the related research in chapter 2. We define our research objective and explain our research process in chapter 3 . We then present our findings in chapter 4 and conclude our paper by discussing and summarizing the results in chapter 5.

\section{Related Research}

One of the drivers of modern e-Business research is the inefficiency caused by lack of interoperability, shown first as countable costs by [31, 38] in a series of studies concerning the American auto industry. According to Legner \& Lebreton [39], interoperability research can be roughly classified as either explorative, which involves identifying interoperability factors or describing the status of interoperability in a given domain, or constructive, which involves developing solutions for overcoming interoperability challenges.

Modern e-Business interoperability research often focuses on SME's (Small and mid-sized enterprises), whose slow e-Business adoption [13, 14, 17] has received a lot of attention. This is because SME's comprise the majority of enterprises in most economies and hence have a major influence on the economy's efficiency (OECD [49]). On the other hand, studies in e.g. the UK, Sweden, and New Zealand, [15, 16, 21] respectively, have shown that SME's are not a homogeneous group but vary greatly both in e-Business use as well as in the factors that influence them in adopting or rejecting e-Business technology. Moreover, these factors do not necessarily reflect 
the companies' business strategy or objectives any way, but may relate to e.g. an individual manager's influence [15], or to available resources and know-how [32, 33, 35]. Studies in developing economies (e.g. [34, 35]) agree for most part with these findings and emphasize that each SME should be viewed as unique with its own set of e-Business implementation issues [6].

Research on e-Business adoption at large and multinational companies (MNC's) is more limited and tends to also be more industry-sector specific. Machner et al. [45], Hetemäki \& Nilsson [47], and Mustonen et al. [48], for example, have analyzed eBusiness drivers specifically in the semiconductor and forest industry. Although industry-specific, the findings reflect $\mathrm{MNC}^{\prime} \mathrm{s}$ as more interested in a strategic, long term business-integration-driven approach that goes beyond single e-Business applications. Direct comparative studies between SME's and large enterprises (e.g. $[46,50])$ consider much lighter e-Business approaches, such as various kinds of web commerce. The studies indicate that SME's are more nimble and flexible adopters of light-weight e-Business applications, and seem to benefit from investing in them, sometimes even more than their larger counterparts. The use and development of the more demanding $\mathrm{B} 2 \mathrm{Bi}$ technologies is, however, typically restricted to larger organizations, which have more resources and more opportunities to profit from supply chain integration $[1,6,22]$. This is further confirmed by earlier EDI studies $[36,37]$ and claimed by the RosettaNet consortium [40].

Constructive e-Business research remains also SME-oriented. Here the European Union funded research projects are most notable. The ATHENA project [18] (built on a number earlier projects) was a major effort to build a common European enterprise interoperability framework that heeds not only ICT, but also knowledge, business and semantic interoperability, and could therefore be used in gathering further research results and for developing interoperable services. It remains unclear, however, what concrete outcomes the ATHENA platform has contributed. The ITAIDE [41] project has proposed cross-border e-Business (eGovernment) solutions while the GENESIS project [42] developed an architecture and a process-and-document modeling approach for allowing SME's to carry out e-Business activities with other SME's, public sector and financial institutions via the GENESIS system. It appears that no SME-to-MNC B2Bi is directly supported. Finally, efforts to simplify e-Business standards testing have been also carried out in global co-operation [20].

According to Legner \& Lebreton [39], analysis on the strategic, organizational and operational issues that relate to interoperability are still missing despite the gamut of research already carried out. The authors argue that although projects such as ATHENA have established a foundation for interoperability research, the focus still remains too technology oriented. By the same token, Smolander \& Rossi [43], who observed an enterprise-wide e-Business architecture development process, found the interplay between the architecture and the organization, and the inevitably raising conflicts and compromises, as more important to manage than mere technical factors. The distinction between enterprise architecture [44] and modern, large e-Business architecture appears increasingly intangible if not already non-existent. Nevertheless, in view of the more recent COIN and COMMIUS projects $[19,26]$, the technologydriven approach persists at least in current interoperability research. 


\section{$3 \quad$ Research Process}

Our initial objective was to study e-Business implementation requirements for specific supply chain networks. We quickly found, however, that the body of knowledge in this area was limited. We were interested in large organizations that operate in heterogeneous business networks comprising also a number of much smaller suppliers and buyers with highly-disparate business profiles, IT investment capabilities and IT implementation skills. As we discuss in our review of the pertinent literature, e-Business research has mainly focused on SME-to-SME or otherwise very homogeneous, "flat", domains, treating small and large organizations often separately or disregarding the concrete constraints that $\mathrm{B} 2 \mathrm{Bi}$ activities may impose on a heterogeneous business environment. As an example of this, a large paper mill attempts to leverage e-Business solutions, but does not succeed because the majority of its partners, who are SME's, are unable to implement and operate the technology.

Our research objective is, therefore, to understand what are the factors that hinder large traditional industry organizations in implementing e-Business solutions. More precisely, we want to investigate and characterize the issues present in these organizations or their business environments that have a negative effect on the organizations' ability to develop or adopt new B2Bi solutions or to make effective use of existing ones. In particular, we want to understand the role of the organizations' business environment in e-Business adoption - our study observes a heterogeneous business network consisting also of small partners. This was in our view necessary in order to understand all the dimensions of real world B2Bi schemes.

\subsection{Research Methodology}

e-Business implementation is a process of developing complex, socio-technical systems that involve various stakeholders, IT resources, business processes and objectives influencing one another. Understanding this process requires exploration in real world contexts, which suit well for studying with qualitative methods [27].

We used as our qualitative research approach Grounded Theory (GT) as described by Strauss and Corbin in [23]. Originally described by Glaser and Strauss in [28] for social sciences, the method has since been employed also for research in various fields owing to its ability to discover novel concepts and develop new theories. GT bases the theory building on induction: Instead of encouraging apriori theorization and hypotheses, the method rather instructs the researcher to start directly with data collection and to arrive, by means of explicitly-specified analytic steps, at a specific theory only based on what has been developed from the data, not on what has been expected or wanted to prove with the data.

The first analysis phase, open coding, involves discovering and labeling concepts that might denote commonalities in the data; concepts that stand for "what is going on" in the part under analysis are considered particularly fruitful for further scrutiny. The concepts are then assorted by assigning them properties. In the second phase, axial coding, the concepts are further developed by defining their relationships. A crucial tool for this is various comparisons that aid in discovering commonalities and differences, and the properties of these variations. GT provides a set of mechanisms 
for carrying out these comparisons, but it is always the researcher's creativity that in the end plays the main role in the analysis. The third and final phase is selective coding, where a final core category is derived from the fully developed categories and thus theory is created.

\subsection{Case Organizations and Interviewees}

Our first criterion in selecting the case organizations was that we wanted them to be located in a limited geographical region where the number and type of potential suppliers as well as the operational environment were similar. The organizations also had to be large enough to be able to impose a notable influence in the region by attracting around them a network of smaller suppliers specialized in serving large industry. Since the heterogeneity of business partners was an important factor for us, we decided to include one large public sector organization along with industry representatives. Existing research has paid some attention to the needs of public sector in relation to e-Business development (e.g. [22, 29, 42]), but not specifically in the context of carrying out day-to-day business interactions - for example, as a purchaser of services and supplies. On this score, we treated the public sector organization similarly to the industry representatives.

Table 1 lists the case study organizations and the position of the interviewees in each organization. Nine manager-level interviewees were selected from both business and IT departments based on preliminary discussions with the organizations. The interviewees were carried according to a list of prepared, open-ended questions that were similar to all participants albeit with slight differences in emphasize depending on the interviewee's background. In total, we accumulated approximately $11 \frac{1 / 2}{2}$ hours of interview material, which was then transcribed to text for analysis. In addition to the interviews we also participated in a meeting involving the managers in Organization D interested in hearing and discussing e-Business issues in relation to their newly-started ERP development project. We used this opportunity for questioning and for observing the discussion.

Table 1. Case organizations

\begin{tabular}{lll}
\hline Label & Description & Interviewee \\
\hline A & City organization. Provides public & IT manager \\
& services. & $\begin{array}{l}\text { Head of Purchasing } \\
\text { Financial director }\end{array}$ \\
& & A paper and pulp mill part of a global \\
B & Hood of maintenance services \\
& A wood products mill part of a global & Head of mill services \\
C & IT manager \\
& A steel mill part of an international & Head of purchases \\
D & consortium. & IT manager of business developments \\
& & Meeting with other managers \\
\hline
\end{tabular}




\section{$4 \quad$ Findings}

Figure 1 depicts our observations of how specific impeding factors affect the organizations' e-Business implementation capability. We have organized the specific factors under three generic classes - IT resources, e-Business knowledge and Business environment, of which IT resources and e-Business knowledge are internal to the organization and in its own control. Each high level category manifests the implications its sub factors impose. The high level factors are ordered according to importance from left to right so that IT resources has, in general, more severe impact than Business environment. The influence between categories and individual factors is marked with arrows.

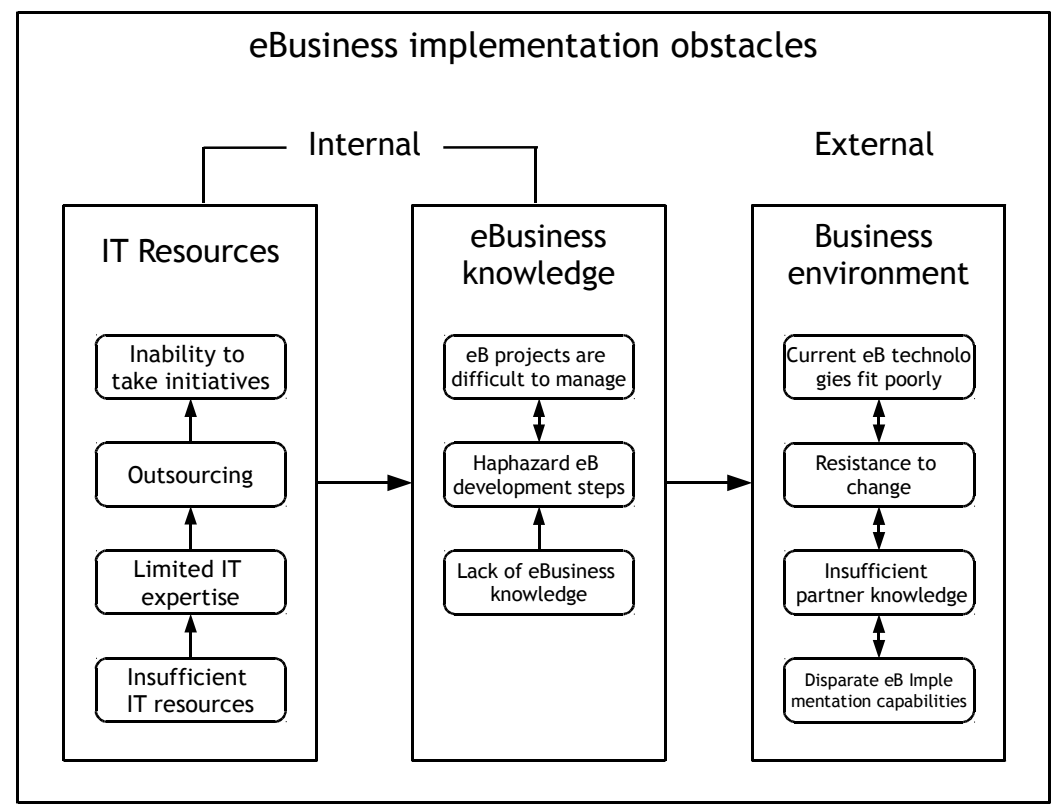

Fig. 1. Factors impeding e-Business implementation

The model was constructed to present the highest level categories resulting from selective coding so that IT resources, e-Business knowledge and Business environment remained the topmost subcategories of the core category e-Business implementation obstacles. Similarly, each subcategory contained a set of its own sub categories, labeled here as factors.

The analysis started with no explicit a priori categories. The interview data were first scanned for words and phrases describing interesting phenomena or common occurrences, with particular emphasis on activity - "what is happening here?" or "what action does this pertain to?". With a number of such labels discovered, we were able to categorize them with comparisons, creating new categories, such as "manual procurement process" and "electronic procurement process", which, while belonging 
to a yet higher level category, differed on a key dimension of one of their shared properties. We carried both open and axial coding more or less simultaneously. In developing the core category and our theory, we abstracted the categories by developing their relationships until we had arrived at 11 factors, belonging to the three high level categories. We derived the factor relationships, shown in the model by arrows, from the category relationships by asking "Do the properties of this category beget any of the major properties of another category?"

We explain our findings according to this model. First, however, we describe the organizations' business environment and e-Business implementation status at the time of the study in order to set the context for our model.

\subsection{The Current Status of e-Business in the Case Organizations}

The business environment is highly heterogeneous. All case organizations operate not only with other large buyers and suppliers, but also with a network of local SME's that are specialized in offering the kind of supplies and services the local large industry needs but does not produce itself. These supplies can be divided into materials and products (Organization A) and into maintenance work and related services (Organizations B, C and D). Other kind of out-sourced services, such as logistics or IT, are primarily acquired from larger providers outside the region.

The business environment is increasingly competitive. The industry organizations (mills) export almost all their production. Competition in their export markets has increased noticeably with globalization, forcing the companies to change their business strategy. B and $\mathrm{C}$ have launched drastic cost cutting programs to regain operational efficiency. Organization D, in contrast, has steered away from direct price competition and chosen as its strategy to make special-grade, per-client-tailored products that also incorporate services for additional value. All organizations have chosen to outsource more and more of the supporting day-to-day business operations (e.g. maintenance work, IT, logistics).

The organizations have successfully adopted electronic invoicing. Electronic invoicing solutions replace printed invoice documents, traditionally sent via mail, with electronic documents that can be exchanged between information systems and processed digitally. For the case study organizations, electronic invoicing has become pervasive quickly. During the last two years organizations B, C and D in particular have grown the share of eInvoices to more than half of all invoices sent or received; and $\mathrm{B}$ and $\mathrm{C}$ will soon start requiring all their purchases to be invoiced electronically. $\mathrm{A}$ and $\mathrm{D}$, in contrast, do not yet want to impose such demands but are rather content to only promoting eInvoicing to partners and offering help in its adoption.

The objectives in using eInvoicing are improved efficiency via reduced manual work and better transparency via more integrated, automated business processes. It also allows for integrating the handling of invoicing data with enterprise resource planning (ERP) systems, which makes it possible to monitor work flows more easily and thus make orders and their status more transparent and easier to predict and plan. 
By using their influence, the large organizations have not only been able to persuade, but in the case of $\mathrm{B}$ and $\mathrm{C}$ and partly $\mathrm{D}$, have also been able to dictate the rules by which this technology is to be used in the immediate business network for their benefit.

Use of other forms of e-Business was limited. Organization $\mathrm{C}$ has made some use of the forest-industry-specific $\mathrm{B} 2 \mathrm{Bi}$ standard in business document exchanges involving other large industry partners. The company has also worked with large partners on tailored interfaces that offer access to its IT services. Organizations A and B have attempted to develop e-Business portals for interactions with SME partners, but these projects have either been postponed due to budget issues or they have been incorrectly focused due to insufficient requirements analysis.

\subsection{Impeding Factors for e-Business Implementation Capability}

\section{IT Resources}

Insufficient IT resources are a major e-Business implementation obstacle. The costcutting strategy the industry organizations in particular have entered has applied also to IT. This has led every organization to outsourcing all but the most essential day-today IT administration and development activities. The trend has become pervasive: Even for IT tasks not (or not yet) outsourced, the staff has been or is to be reduced as low as possible and may be moved off-site for consortium-wide, centralized IT management - this is particularly true in organizations $\mathrm{B}$ and $\mathrm{C}-$ and where special expertise is to be needed, it will be acquired from outside as necessary instead of keeping (expensive) IT expertise on a regular pay-roll. This has limited the IT expertise the organizations have at their disposal.

"Within this organizational unit, there is only I and [another manager name] left who can any more give answers to such questions [pertaining to IT and e-Business]."

"We've been talking about this [outsourcing and centered IT management] for some years already... the objective of course is to make everything a lot easier, so we need to keep fewer IT experts. And we need not hire new IT people when employees retire. Yes, cutting costs is driving all this."

"Instead of doing these [IT tasks] ourselves, we can now buy them as a service from [provider]."

Outsourcing. While believed to cut costs without impeding on IT capability, outsourcing of IT appears to have made, with less in-house IT expertise available, the organizations increasingly dependent on third party providers, who have thus gained more control on what kind of systems are used and how they are built and tailored. These providers do not necessarily share the same interests as defined in the organizations' IT strategies, and do not hence promote new IT paradigms, such as eBusiness technologies. Rather, they may support the development of systems that make e-Business-related integration tasks actually more difficult due to undocumented interfaces and missing planning for future expandability. There was evidence of this already having an effect. 
"We are sure [the system provider] will take care of these aspects... that the XML support will be $O K$ in the new system. I am sure they understand this need and know how to handle it [according to our requirements now and in the future]." These needs related to the XML-support had not been communicated to the provider, nor was the person able to express them in anything but very vague terms.

"The problem with this [provider] system is that it is difficult to make it work for this [e-Business use], as it is has always been difficult to read data from it [in any other way than the provider wants] and even today we find it difficult to write data into the database component." These problems had affected this organization's earlier e-Business project.

Inability to take initiatives. Reduced IT resources and the reliance on outsourcing has led to an inability to invest in long term objectives and to discover and take initiatives whose goals lie beyond the day-to-day "sphere of focus" - that is, to make use of IT proactively in order to create new usage scenarios or to support the business strategy in novel ways. This contributes in particular to issues discussed under "eBusiness knowledge" This is also in contrast to organizations B and C's past strategy for developing IT as a long term tool for achieving the industry leadership.

"The primary objective for any IT project we can implement today [heeding the costs-saving strategy] has to be... it has to be able to not only to remove costs, or to make something "better"... that is not enough... the project has to result in jobs being eliminated... now. Unless you can show that, it won't be financed."

\section{e-Business Knowledge}

Organizations are lacking e-Business knowledge and therefore progress haphazardly with no conscious e-Business strategies defined.

Lack of e-Business knowledge. Our interviews showed that the notion of e-Business was not only vague and poorly understood, but it was also treated disparately amongst the interviewees. Although all interviewees were somewhat familiar with the term or its variants, each gave a unique definition for what they believed e-Business meant. For example, e-Invoicing, which all interviewees were familiar with, was treated as a separate technology and often only associated with other e-Business technologies upon questioning on possible links between the organization's conceivable future eBusiness objectives. In general, the interviewees approached the topic from a point of view closely tied to their past, professional experience and their current position in the organization.

"In my view e-business is... I understand it as belonging to the marketing side... As in our industry there was this hype some 10 years ago that all buying and selling would go to online auction and market sites."

"It is, I think, transmitting data in an electronic form via internet. So there is less need for manual work when the data are transmitted. And it enables huge data storages which people can peruse."

"It means that we make the transactions between our partners electronic between both clients and suppliers. This can be done in two ways: [long technical explanation omitted]" 
Haphazard e-Business development steps. Lack of e-Business knowledge has resulted in no conscious organization-wide e-Business strategies defined. The organizations were rather "groping" their way toward something undefined in small, haphazard steps rather than following a organizationally-agreed-on path leading towards specific objectives. The ability to discuss and introduce e-Business-related topics to day-to-day business planning relied on few, select individuals and their interest or motivation to work on the topic and influence the organization. Since eBusiness had remained so little understood, managers could also easily disregard it with impunity in view of their superiors and peers.

Lack of e-Business knowledge and organizational understanding on its implications had together further led to the incorrect view that e-Business is simply an IT topic, while in fact it involves, due to its spanning the whole organizational architecture, inevitably not only IT, but the whole gamut of business processes, related business objectives and information systems. Successful e-Business development has to heed know-how across business units and involve the knowledge of domain experts.

Consequently, e-Business projects are difficult to manage. The danger that an eBusiness project fails due to improper requirements analysis seems alarmingly high. Organizations $\mathrm{C}$ and $\mathrm{B}$ in particular expressed great concern over this matter and even appeared wary of starting e-Business initiatives due to the experience of how difficult it is to manage e-Business requirements. For organization A, an e-Business project being developed at the time of the study appeared to be incorrectly focused due to a flawed and partially-skipped analysis phase. The analysts had incorrectly relied on their previous business and IT experience and this way made innocent-looking, "selfevident" presumptions that were inappropriate in an e-Business domain.

"That project they are developing for us... well it is completely useless from our requirements point of view. We would rather need the catalog service kind of solution ... Lacking it is actually a bottleneck for us."

"The [light-weight e-Business project the mill has tried to develop] has been again postponed; now it was piloted but the pilot failed - the system had been specified incorrectly. They've tried to fix it again and again but they don't seem to get it working right ... and it is now being re-analyzed for the requirements and then we reimplement it, but only in case it won't be too expensive."

\section{Business environment}

The organizations' business network poses external factors that make implementing eBusiness solutions more difficult.

A heterogeneous business network consists of partners that have disparate eBusiness implementation capabilities. This can be a major hindrance. SME partners especially are notable here, as the interviewees had a strong opinion that their SME partners would be incapable of adopting such e-Business technologies as would allow the large organizations to make also other transactions than just invoices electronic. In these transactions product orders, inquiries, confirmations etc. would be exchanged as standardized, electronic business documents between each partners' information systems. Electronic invoicing solutions have been able to overcome this barrier because there were third party services available which the SME partners could tap 
into in case they were unable or unwilling to implement the technology. There were no such solutions available for other, more demanding B2Bi technologies.

Other large organizations can also pose problems. As $\mathrm{C}$, for example, has experienced, there is no guarantee that the other partner, no matter what size, is yet capable or willing to participate in electronic transactions beyond eInvoicing. Individual managers may wield significant power over such decisions. Their influence is fueled by the already mentioned factors of lack of e-Business knowledge and lack of e-Business strategies.

Insufficient partner knowledge. The organizations are poorly acquainted with most of their partners' IT capability and e-Business-related needs. This is particularly true with SME's, but it is also a limitation with larger partners. In the past, the organizations have not needed to develop this kind of knowledge. But e-Business solutions require for most profit for the partners to co-operate, and lack of knowledge on possible mutual interests, or areas where both organizations or even a group of organizations could benefit from working together on e-Business implementation, affects the network's ability to collaborate.

"About our SME partners... well, we know nothing of what is going on there, what they can do, what they need. It is a completely blank area for us!'”

There is also resistance to change in the business network. This is, in part, attributed to a kind of chicken and egg situation: There is limited motivation even for a large organization to invest in and develop capability for something that others are not (apparently) yet doing - the fear is it might turn out to an entirely wrong standard or approach as the technology "catches on someday." Other organizations may also want to pursue only their selected e-Business standard.

"We see little activity regarding this amongst our partners... I feel they tend to think, let's wait and see. So there is perhaps some resistance to change due to our industry sector."

"It may be the partner already has another standard in use, and if they are a customer... a large one... we just have to go by that standard and implement a mapping between that and our own."

"For some customers our industry is not their primary business, so they see no incentive to implement our industry standards."

The mills thought that in their traditional industry sectors it would be difficult to gain competitive advantage with e-Business technologies today. They also pointed out that their industries are rather followers than early adopters or IT technology drivers. Therefore competitors - internal or external to the network - were not expected to make any quick, major breakthroughs either, or gain unexpected competitive advantage through $\mathrm{B} 2 \mathrm{Bi}$.

"This [e-Business development] is 'business as usual' for us [in our industry]. No one here gains a competitive advantage from it ... it is something we all just need to eventually do."

Finally, the current e-Business technologies fit poorly for these heterogeneous eBusiness environments. The technologies seem aimed at different kind of networks where partners are more alike both in terms of their implementation capability and eBusiness needs. The current $\mathrm{B} 2 \mathrm{Bi}$ frameworks tend to be industry sector standards, 
yet in these networks cross-industry partnerships are common. This may pose more work on one of the partners, to whom the standard is new or little used. Even when the partners can operate with an "industry native" standard, they still need to agree on a large number of details pertaining to the documents being exchanged, and this raises the bar for engaging in such transactions with partners with whom only a limited number of transactions is expected. There have also emerged e-Business development needs for these networks that are entirely beyond the objectives of currently-available tools.

"[Even when we need not map between standards], so we can use papiNet, the papiNet document, it contains a few mandatory fields and then a large number of optional fields that have to be nonetheless agreed on, whether the field is used and how it is used and so forth and this has to be done always with every partner... it is a standard but it is not, like, throughout in that sense."

"It is not realistic with SME's. On the other hand, the profile of our SME and larger suppliers is so different, the volumes on SME's are small and their business is more like services. So there has perhaps not been a business case for us to invest resources into developing $B 2 \mathrm{Bi}$ with these partners."

"We've been thinking about an electronic procurement system, but ... we are missing a tool/technology for managing the product data as a universally accessible catalogue or similar [e-Business service]. [Therefore] We cannot move on with this concept."

\section{Discussion and Conclusions}

Our research objective was to investigate and characterize the issues that hinder large traditional non-IT industry organizations in implementing e-Business solutions. Our intent was to expand current research by, first, involving a class of organizations that has previously been little studied, and, secondly, by taking into account the heterogeneous nature of the business environment in which the organizations collaborate.

Our findings indicated that the organizations were facing not any single, dominant obstacle but rather a mixture of closely-intertwined, accumulative challenges. Lack of IT resources and expertise had resulted in the organizations' relying increasingly on outsourcing. But this seemed to rather limit than support their ability to take proactive, long-term IT development initiatives such as would be required for implementing e-Business. The organizations were also lacking e-Business knowledge and thus had no conscious, organizationally-agreed e-Business strategies defined. As a result, they were progressing with uncertain, haphazard steps that supported no specific e-Business objectives. A major factor here was that without sufficient resources and knowledge, e-Business development projects, which appear particularly challenging for requirements engineering, had became very demanding to carry out. Finally, the heterogeneous business environment posed additional challenges. The business partners had highly-versatile e-Business implementation capabilities, which 
impeded e-Business initiatives in the network. The available e-Business technologies also fit poorly for use in this environment.

In total, we established 11 factors, which we categorized under three higher level classes - IT resources, e-Business knowledge and the business environment - the first two of which were mainly internal to the organizations, while factors under the business environment were external and not in the organization's immediate control. We developed the factors into a model showing their relationship and the order of severity.

In view of earlier e-Business research, we were surprised to find that some eBusiness adoption barriers associated with SME's, such as insufficient resources and knowledge [32, 33, 35], and the influence wielded by a single manager in e-Business decision making [15], could also afflict very large organizations when driven to slim down IT spending to minimum. The organization's size alone will not guarantee eBusiness implementation capability.

We consider the issues discovered about the heterogeneous business environment to be very important. The current e-Business technologies, such as B2Bi framework standards, fit poorly for this kind of environment due to the wide variety of eBusiness implementation capabilities found there and the propensity of these networks to span industry sectors. This is not surprising, as, according to our best knowledge, heterogeneous business environments have not been studied previously from e-Business requirements' point of view. Instead, the B2B interaction environment is often expected to be SME-to-SME oriented or otherwise "flat" and more homogeneous than we found it to be. It is possible that this explains some of the difficulties industry elsewhere, too, has experienced in moving towards deeper business-to-business integration.

Our plan is to follow up this research by further exploring the SME-MNC B2B interactions, which pose the most difficult interoperability obstacle. We want to understand the constituents of these B2B scenarios and specify concrete interoperability requirements for more feasible e-Business implementations in the case study networks.

\section{References}

1. Kotinurmi, P.: E-Business framework enabled B2B integration. Doctoral Dissertation, Helsinki University of Technology, Department of Computer Science and Engineering, Software Business and Engineering Institute (2007)

2. Karuranga, E., Frayret, J.M., D'Amours, S.: Measurements and Determinants of Supply Chain Collaboration. CIRRELT-2008-17, CIRRELT (2008)

3. UN/EDIFACT, http: //www . unece.org/trade/untdid/welcome.htm

4. ASC X12, https: / /www. X12.org

5. Salminen, A.: EDIFACT for business computers: has it succeeded? Standard View 3, 33-42 (1995)

6. Pesonen, T.: Quality Standards in e-Business Software Development. Master of Science Thesis, Lappeenranta University of Technology (2009) 
7. Nurmilaakso, J.M.: Adoption of e-business functions and migration from EDI-based to XML-based e-business frameworks in supply chain integration. International Journal of Product Economics 115, 721-733 (2008)

8. Nurmilaakso, J.M., Kotinurmi, P., Laesvuori, H.: XML-based e-Business frameworks and standardization. Computer Standards \& Interfaces 28, 585-599 (2006)

9. Medjahev, B., Benatallah, B., Bouguettaya, A., Ngu, A.H.H., Elmagarmid, A.K.: Business-to-business interaction issues and enabling technologies. The International Journal on Very Large Data Bases 12, 59-65 (2003)

10. Alonso, G., Casati, F., Kuno, H., Machiraju, V.: Web Service Concepts, Architectures and Applications. Springer, Berlin (2004)

11. Bih, J.: Service oriented architecture (SOA) a new paradigm to implement dynamic ebusiness solutions. ACM Ubiquity (2006)

12. Gamage, A.H.H.: E-Business Impact on SCM in the apparel industry operating between a developing and a developed economy. Brunel University, Buckinghamshire Chilterns University College, Faculty of Enterprise and Innovation (2007)

13. OECD Information Technology Outlook 2004. OECD (2004)

14. Li, M.S., Cabral, R., Doumeingts, R., Popplewell, K.: Enterprise interoperability research roadmap. Final version (Version 4.0),

http://ftp.cordis.europa.eu/pub/ist/docs/directorate_d/ e-Business/ei-roadmap-final_en.pdf

15. Fillis, I., Johannson, U., Wagner, B.: Factors impacting on e-Business adoption and development in the smaller firm. International Journal of Entrepreneurial Behaviour \& Research 10, 178-191 (2004)

16. Beheshti, M.H., Salehi-Sangari, E.: The benefits of e-Business adoption: an empirical study of Swedish SMEs. Service Business 1, 233-245 (2007)

17. Ramayah, T., Yan, L.C., Sulaiman, M.: SME e-readiness in Malaysia: Implications for Planning and Implementation. Sasin Journal of Management 11, 103-120 (2005)

18. Anastasiou, M., et al.: ATHENA Interoperability Framework, AIF (2010)

19. Coin IP Enterprise Collaboration \& Interoperability, http: / / www . coin-ip.eu/

20. CEN workshop Agreement on: Feasibility Study on e-Business Interoeprability Test Bed (GITB). CEN/ISSS Interoperability e-Business Forum. CWA 16093:2010 (E) (2010)

21. Rashid, M.A., Al-Qirim, N.: E-Commerce Technology Adoption Framework by New Zealand Small to Medium Size Enterprises. Research Letter of Information and Mathematical Science 2, 63-70 (2001)

22. Tan, Y.H., Bjorn-Anderson, N., Klein, S., Rukanova, B.: Accelerating Global Supply Chains with IT-Innovation. Springer, Heidelberg (2011)

23. Strauss, A., Corbin, J.: Basics of Qualitative Research: Grounded Theory Procedures and Techniques. SAGE Publications, Newsbury Park (1990)

24. Glissmann, S.: IT Service-Oriented Investment Analysis, A Comparison of In-House versus Software-as-a-Service Deployment Solutions. Dissertation no. 3685, Pro BUSINESS Verlag, Berlin (2010)

25. Schroth, C., Pemptroad, G., Janner, T.: CCTS-based Business Information Modelling for Increasing Cross-Organizational Interoperability. In: Enterprise Interoperability II. New Challenges and Approaches. Springer, Heidelberg (2007)

26. Ling-Hong, T.: Commius architecture (final version). Commius ICT 2007 GA 213876 (2007)

27. Seaman, C.B.: Qualitative Methods in Empirical Studies of Software Engineering. IEEE Transactions on Software Engineering 25, 557-572 (1999)

28. Glaser, B., Strauss, A.: Discovery of Grounded Theory, Aldine, Chicago (1967) 
29. PEPPOL (Pan-European Public Procurement Online), http: / /www . peppol.eu/results

30. Barratt, M.: Understanding the meaning of collaboration in the supply chain. Supply Chain Management: An International Journal 9, 30-42 (2004)

31. Interoperability cost analysis in the US automotive supply chain. Planning report 99-1, Maryland: National Institue of Standards and Technology (1999)

32. Abid, A.A., Rahim, M.M., Scheepers, H.: Experienced Benefits and Barriers of e-Business Technology Adoption by SME suppliers. Communications of the IBIMA. J. (2011)

33. Pulli, H.: Factors Affecting the Adoption of E-Invoicing in South Karelia. Master's Thesis, Lappeenranta University of Technology (2005)

34. Khatibi, A., Thyagarajan, V., Seetharaman, A.: E-commerce in Malaysia: Perceived Benefits and Barriers. Vikalpa 28, 77-82 (2003)

35. Olatokun, W., Kebonye, M.: e-Commerce Technology Adoption by SMEs in Botswana. International Journal of Emerging Technologies and Society 8, 42-56 (2010)

36. da Silva, M.M.: Challenges for EDI Adoption by Small and Medium-size Enterprises. In: dos Reis, A.P., Isaías, P. (eds.) IADIS International Conference e-Society 2003, pp. 603-607 (2003)

37. Andersen, V.K., Henriksen, H.Z.: B2B E-commerce Diffusion: The Efficacy of Institutional Discourse. In: Doukidis, G., Mylonopoulos, N., Pouloudi, N. (eds.) Social and Economic Transformation in the Digital Era. Idea Group Publishing, Hershey (2003)

38. Brunnermeier, S.B., Martin, S.A.: Interoperability costs in the US Automotive Supply Chain. Supply Chain Management 7, 71-82 (2002)

39. Legner, C., Lebreton, B.: Business Interoperability Research - Present Achievements and Upcoming Challenges. Electronic Markets 17, 176-186 (2007)

40. Cartwright, J.: RosettaNet Automated Enablement. In: Material Composition Workshop, RosettaNet, August 30 (2004)

41. ITAIDE Project, http://www.itaide.org

42. GENESIS Project, http://genesis-fp7.eu

43. Smolander, K., Rossi, M.: Conflicts, Compromises, and Political Decisions. In: Siau, K., Erickson, J. (eds.) Principle Advancements in Database Management Technologies: New Applications and Frameworks, pp. 82-104. IGI Global (2010)

44. Ross, W.J., Weill, P., Robertson, D.C.: Enterprise Architecture as Strategy; Creating a Foundation for Business Execution. Harvard Business School Publishing, Boston (2006)

45. Macher, J.T., Mowery, D.C., Simcoe, T.S.: E-business and disintegration of the semiconductor industry value chain. Industry and Innovation 9, 155-181 (2002)

46. Daniel, E., Grimshaw, D.J.: An Exploratory Comparison of Electronic Commerce Adoption in Large and Small Enterprises. Journal of Information Technology 17, 133-147 (2002)

47. Hetemäki, L., Nilsson, S.: Information Technology and the Forest Sector. Final Report by the IUFRO Task Force, IUFRO World Series, vol. 18 (2003)

48. Mustonen, T., Karvonen, M., Soininen, L., Hellsten, K., Kässi, T.: Digitizing Business Processes in the Intersection of Energy, Forest and ICT Industries. Lappeenranta University of Technology, Technology Business Research Center, Research Report 13 (2008)

49. OECD Small and Medium Enterprise Outlook, OECD (2002)

50. Byrne, J., Singh, M., Tian, X.: Does size matter? A study comparing e-business implementation in large and small companies in Australia. In: Karmaker, N., Isaias, P. (eds.) Proceedings of the IADIS International Conference E-Commerce 2005, pp. 251-258 (2005) 